Part of Journal of Research of the National Bureau of Standards, Volume 22, March 1939

\title{
PRINTING TESTS OF EXPERIMENTAL BOOK PAPERS
}

\author{
By Merle B. Shaw and Robert H. Simmons ${ }^{1}$
}

\section{ABSTRACT}

In connection with the previously published study of the "Effect of filling and sizing materials on stability of book papers," RP1149, comparative measurements of printing quality have been made on 45 of the experimental papers. Smoothness, oil penetrability, and air permeability were determined by laboratory tests at the Bureau; the composite effect of all the factors that affect printing, by actual printing trials at the Government Printing Office.

For the same pulp furnish, the smoothness values of the papers were about the same for precipitated calcium carbonate and clay, and less for natural calcium carbonates, titanium dioxide pigments, and zine sulfide pigments. With respect to their influence on the oil penetrability of the paper, the order in decreasing rapidity of penetration was: Precipitated calcium carbonate, natural calcium carbonate, zinc sulfide pigments, titanium dioxide pigments, and clay. Ranked according to the degree to which they increase air permeability, the order of the fillers was the same as for oil penetration.

The net resultant of all the factors that affect printing is shown by actual printings. In general, the offset printings were of better quality than the letterpress, and the text better than the illustrations. Ratings of the offset printings as to relative amount of "show through" are given. The calcium carbonatefilled papers gave the best results, but it is believed that printing conditions could have been adjusted to suit each type of paper, and that more satisfactory results would then have been obtained with either process.

\section{CONTENTS}

Page

I. Introduction

II. Paper samples

III. Testing methods

1. Laboratory

2. Printing

IV. Test results

\section{INTRODUCTION}

A study made at the Bureau on the effect of filling and sizing materials on the stability of book papers was recently published. ${ }^{2}$ The study was concerned primarily with the characteristics directly related to the stability of paper. Since book papers must fulfill printing requirements, however, the scope of the work has been expanded to include comparison of the papers from the standpoint of printing quality also. The additional data are here reported to supplement the results obtained in the earlier investigation.

1 Associate Chemist, United States Government Printing Office.

2 J. Research NBS 21, 671 (1938) RP1149. 
The manufacture of the experimental papers was described in the previous publication. The fillers used were representative of several types, both natural materials and manufactured pigments. They comprised one clay; two titanium pigments, titanium dioxide, and a composite of titanium dioxide and barium sulfate; two zinc sulfide pigments, zinc sulfide, and a composite of zinc sulfide and barium sulfate; and two calcium carbonates, one precipitated and one a natural product, water-ground. The fibrous materials employed were sulfite pulp and soda pulp of the ordinary book-paper grade; three "purified" wood pulps produced by special cooking and bleaching treatment to obtain high purity and strength; new rags, the grade known commercially as No. 1 white shirt cuttings; and two grades of old rags, No. 1 old whites and "twos and blues."

The test data on the properties which have a considerable influence on the printability of the paper are repeated here. The additional data given consist of laboratory measurements of other characteristics more directly related to the performance of paper in the printing processes and results of observations of actual printings. The laboratory measurements were made at the Bureau; the paper samples were printed at the Government Printing Office.

\section{PAPER SAMPLES}

Forty-five of the seventy-two experimental papers made in the stability study were selected for the tests of printing quality. They were representative of all the fiber and filler combinations reported in the previous publication.

\section{TESTING METHODS}

\section{LABORATORY}

The laboratory tests made for measuring the printing quality of the book papers were smoothness, oil penetrability, and air permeability. Although no methods for determining these qualities have been adopted as standard by the Technical Association of the Pulp and Paper Industry, the methods used in this work are widely employed by Government and by commercial laboratories.

Smoothness is one of the most important properties of paper from the printing standpoint. In letterpress work the printing pressures are high, and part of the ink between the paper and the hard printing block is therefore pressed out, into the recesses between the surface fibers if the paper is rough, or at the edges of the surface of contact if the paper is smooth. Consequently, if there is not uniform contact between the paper surface and the inked printing plate, loss of detail in the reproduction of either solid print or halftones results.

The smoothness of the paper surfaces was measured with a Bekk smoothness tester, and is expressed as the number of seconds required for $10 \mathrm{~cm}^{3}$ of air at 0.5 atmosphere pressure to pass between $10 \mathrm{~cm}^{2}$ of the paper surface and an optically flat surface which is held against it by a pressure of $10 \mathrm{~kg}$. The tests were made at $21^{\circ} \mathrm{C}\left(70^{\circ} \mathrm{F}\right)$ and 65 -percent relative humidity (standard paper-testing conditions), with the papers tested being in hygrometric equilibrium with the atmosphere of the test room. The values reported are the averages of the measurements on both the felt and the wire sides of the sheets. 
Softness of paper also is important in determining printing quality. If the thickness of the paper is somewhat variable, or the letterpress plates slightly irregular, the paper-and in the offset process, the rubber blanket also - should by its compressibility equalize these irregularities. For a given type of paper, with the same smoothness the softer paper will give the better printing results, other things being equal. No measurements of softness were made on the test papers, however, as the value of the present instruments available for the purpose is not yet well known.

The efficiency of the sizing of nonprinting papers is judged by its effectiveness in preventing the spread and penetration of watery liquids, such as writing ink. The effect with printing ink may not be the same. The penetration of printing ink into paper is due primarily to the vehicle used with the pigment. The resistance of paper to "feathering" of writing ink is, therefore, not a measure of the resistance to inks having an oil base. Printing ink consists essentially of a suspension of finely ground pigment in a suitable oil. Since the sizing values reported relate to water penetration, the data are not applicable for comparing the papers from the printing standpoint. To obtain pertinent data the resistance to penetration of printing ink was evaluated with oil instead of water.

The test was made by the "oil drop" method. The time of penetration through the sheet was found by allowing a drop of USP quality castor oil to fall on one side of the paper and measuring the time, in seconds, required for the oil to penetrate the sheet. The end point of the penetration was taken when the spot on the under surface of the paper was uniformly translucent in appearance. The outlet of the delivery tube for the oil was of such size that 25 drops of distilled water at $21^{\circ} \mathrm{C}$ equalled $1 \mathrm{ml}$. The values are the averages of the rates of penetration determined from each side of the paper.

The ink used in printing processes dries or hardens by oxidation of the oil vehicle, and by absorption of the oil by the paper. In actual practice, the drying results from a combination of both. In general, the oxidation is a much slower process, and if the paper does not absorb the oil readily, the ink will dry too slowly and it will be prone to "set off" and become smudged on contact with adjacent sheets. On the other hand, if the oil penetrates too rapidly, too much vehicle will leave the image, and a chalky film will result. Also if the oil penetrates too rapidly, the sheet tends to become transparent and the printing may "show through" the opposite side of the paper, especially if a large amount of ink has been required to obtain a solid print. The oil penetration test differs from actual printing by using an excess of oil and allowing it to penetrate completely through the sheet, but the relative penetrability of the papers to printing ink should be of the same order.

Air permeability is not known to be definitely correlated with printing quality, but inasmuch as it relates to the passage of air through paper, it may be of assistance in predicting the permeability of the paper also to liquids, such as oil, that do not materially swell cellulose. Since the test measures the flow of air through the minute passages within the fibers themselves and the spaces between the fibers, it likewise holds possibilities for evaluating and controlling the structure 
of the sheet. Keeping the sheet open and bulky is usually considered desirable for optimum printing quality.

The instrument and testing method used for measuring the air permeability were developed at the Bureau and have been described in detail in previous publications. ${ }^{3}$ The test consists in measuring the volume of standard air which passes in unit time through a unit area of the material when forced by a unit pressure difference between the surfaces of the sheet. Standard air, for the purposes of this test, is defined as air at $21^{\circ} \mathrm{C}, 65$-percent relative humidity, and a pressure of one atmosphere.

\section{PRINTING}

To afford comparison of the papers for the composite effect of all the factors which affect printability, the papers were submitted to actual printing tests. Since the letterpress and offset processes are the most commonly used with book paper for mass production, they were the only processes considered. The papers were compared with two commercial book papers, described as "machine-finish" and "offset" and used for regular work at the Government Printing Office, in a run made by the procedure regularly employed. The printings were made on one side of the sheet by the letterpress process, in which an inked relief surface is pressed onto the paper, and on the other side by the offset process in which the impression instead of being made directly upon the paper is first received by a rubber blanket, from which it is transferred to the paper. The images printed by both processes consisted of text and halftones.

\section{TEST RESULTS}

The smoothness measurements of the test papers are given in the table. The time required for the air to pass over the surface of the paper increases with increasing smoothness of sheet, therefore, a low reading indicates comparatively rough paper; a higher reading, smoother paper. For best printing results the papers should have been more highly calendered, as the machine finish obtained on the small calender stack at the Bureau is possibly not as smooth as commercial machine finish.

Fillers, because of their greater smoothability and smaller particle size, respond more readily than fiber to the pressure of the calender rolls used in the papermaking process to press and smooth the paper, and their presence, therefore, increases the smoothness of the paper surface. Although only a limited number of papers were made and smoothness was not of primary importance in their manufacture, the results indicate a general trend. For the same pulp furnish the smoothness values of the papers were about the same for precipitated calcium carbonate and for clay, and less for natural calcium carbonates, titanium dioxide pigments, and zinc sulfide pigments. Although the manufacturers of the titanium dioxide and the zinc sulfide pigments state that only small proportions are generally used in paper, since the study for which the papers were made was concerned mainly with the effect of the pigments on stability, 5 and 15 percent were each used in the experimental runs. The amount of clay added was

${ }^{3}$ BS J. Research 12, 567 (1934) RP681; BS J. Research 12, 587 (1934) RP682. 
15 percent; of calcium carbonate, 15 or 30 percent. The test results should be regarded as applying only to the materials used, which were representative at the time the work was done. The relationship may be changed with further improvement in quality of the materials with further advance in manufacturing technique.

For the same filler furnish, the old-rag papers were the highest in smoothness; the sulfite-soda, new rag, and purified wood pulps $A$ and $C$ (mixture) papers were intermediate; and the purified wood pulp $D$ was lowest. Comparison of the tests with the printings indicates that the papers having the higher smoothness values gave the better letterpress printing results. The offset process is less exacting than the letterpress with respect to smoothness. 
TABLE 1.-Test data on the experimental book papers

\begin{tabular}{|c|c|c|c|c|c|c|c|c|c|c|c|c|c|}
\hline \multirow{2}{*}{$\begin{array}{c}\text { Pa- } \\
\text { per } \\
\text { ma- } \\
\text { chine } \\
\text { run } \\
\text { num- } \\
\text { ber }\end{array}$} & \multirow[b]{2}{*}{ Fiber used } & \multirow[b]{2}{*}{ Filler used } & \multicolumn{10}{|c|}{ Tests of papers ${ }^{3}$} & \multirow{2}{*}{$\begin{array}{l}\text { Rating of } \\
\text { "show" } \\
\text { through"- } \\
\text { offset print- } \\
\text { ings }{ }^{5}\end{array}$} \\
\hline & & & $\begin{array}{l}\text { Weight: } \\
25 \text { by } 40 \\
\text { inches, } \\
500 \text { sheets }\end{array}$ & $\begin{array}{c}\text { Thick- } \\
\text { ness }\end{array}$ & Filler 1 & Resin 1 & $\begin{array}{l}\text { ity } \\
\text { (glass } \\
\text { elec- } \\
\text { trode } \\
\text { meth- } \\
\text { od) }\end{array}$ & $\begin{array}{l}\text { Degree } \\
\text { of sizing } \\
\text { (dry in- } \\
\text { dicator } \\
\text { method) }\end{array}$ & \begin{tabular}{|c|} 
Opac- \\
ity \\
(con- \\
trast \\
ratio)
\end{tabular} & $\begin{array}{c}\text { Smooth- } \\
\text { ness 4 } \\
\text { (Bekk } \\
\text { instru- } \\
\text { ment) }\end{array}$ & $\left|\begin{array}{c}\text { Oil } \\
\text { pene- } \\
\text { tration }\end{array}\right|$ & $\begin{array}{c}\text { Air permea- } \\
\text { bility }\end{array}$ & \\
\hline 1133 & Sulfite pulp, $50 \%$; soda pulp, & None... & $\begin{array}{r}\text { Pounds } \\
57.6\end{array}$ & $\begin{array}{c}\text { Inch } \\
0.0035\end{array}$ & Percent & $\left|\begin{array}{c}\text { Percent } \\
\mathbf{0 . 3}\end{array}\right|$ & $\begin{array}{l}\mathrm{pH} \\
6.9\end{array}$ & Seconds & $\begin{array}{c}\text { Percent } \\
81\end{array}$ & $\begin{array}{c}\text { Seconds } \\
35\end{array}$ & $\left|\begin{array}{c}\text { Seconds } \\
158\end{array}\right|$ & $\mathrm{cm}^{3} / \mathrm{sec} / \mathrm{m}^{2} / \mathrm{g} / \mathrm{cm}^{2}$ & 47 \\
\hline 1143 & $\begin{array}{l}50 \% . \\
-. d 0\end{array}$ & -......do_. & 55.9 & .0037 & 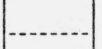 & .9 & 5.8 & 49 & 83 & 40 & 145 & 62.0 & 46 \\
\hline $\begin{array}{l}1130 \\
1137 \\
1140 \\
1141 \\
1142\end{array}$ & \begin{tabular}{|c|} 
\\
$-\ldots$ do
\end{tabular} & 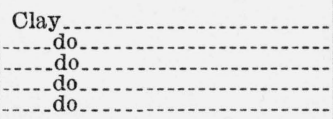 & $\begin{array}{l}55.5 \\
55.6 \\
56.1 \\
55.6 \\
55.7\end{array}$ & $\begin{array}{l}.0035 \\
.0037 \\
.0036 \\
.0037 \\
.0036\end{array}$ & $\begin{array}{l}10.1 \\
10.6 \\
10.0 \\
11.8 \\
12.6\end{array}$ & $\begin{array}{l}.2 \\
1.6 \\
1.0 \\
1.2 \\
1.0\end{array}$ & $\begin{array}{l}5.3 \\
5.5 \\
5.9 \\
5.2 \\
6.5\end{array}$ & $\begin{array}{l}40 \\
42 \\
47 \\
48\end{array}$ & $\begin{array}{l}87 \\
88 \\
88 \\
89 \\
89\end{array}$ & $\begin{array}{l}68 \\
65 \\
68 \\
58 \\
67\end{array}$ & $\begin{array}{l}103 \\
112 \\
111 \\
105 \\
110\end{array}$ & $\begin{array}{l}94.0 \\
98.0 \\
81.5 \\
96.0 \\
91.7\end{array}$ & $\begin{array}{l}45 \\
37 \\
38 \\
21 \\
22\end{array}$ \\
\hline $\begin{array}{l}1147 \\
1145 \\
1149\end{array}$ & 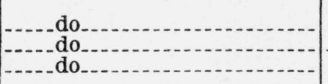 & $\begin{array}{l}\text { Titanium pigment } \boldsymbol{A} \\
\text { Titanium pigment } \boldsymbol{B}_{\mathrm{B}} \\
\end{array}$ & $\begin{array}{l}54.9 \\
57.1 \\
56.5\end{array}$ & $\begin{array}{l}.0035 \\
.0037 \\
.0035\end{array}$ & $\begin{array}{r}9.0 \\
3.1 \\
83.2 ; 6.6\end{array}$ & $\begin{array}{r}1.0 \\
1.9 \\
1.1\end{array}$ & $\begin{array}{l}5.2 \\
5.6 \\
5.2\end{array}$ & $\begin{array}{l}38 \\
59 \\
45\end{array}$ & $\begin{array}{l}94 \\
90 \\
92\end{array}$ & $\begin{array}{l}48 \\
36 \\
46\end{array}$ & $\begin{array}{r}108 \\
118 \\
96\end{array}$ & $\begin{array}{l}85.9 \\
65.9 \\
98.2\end{array}$ & $\begin{array}{r}4 \\
23 \\
28\end{array}$ \\
\hline $\begin{array}{l}1150 \\
1151 \\
1153\end{array}$ & 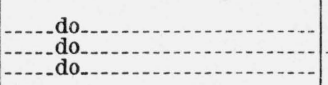 & $\begin{array}{l}\text { Zinc sulfide pigment } A \\
\text { Zinc sulfide pigment } B \\
\end{array}$ & $\begin{array}{l}56.0 \\
55.1 \\
55.0\end{array}$ & $\begin{array}{l}.0035 \\
.0034 \\
.0033\end{array}$ & $\begin{array}{r}9.4 \\
2.3 \\
76.2 ; 5.1\end{array}$ & $\begin{array}{r}1.1 \\
1.9\end{array}$ & $\begin{array}{l}5.8 \\
5.7 \\
5.1\end{array}$ & $\begin{array}{l}44 \\
59 \\
47\end{array}$ & $\begin{array}{l}94 \\
88 \\
94\end{array}$ & $\begin{array}{l}44 \\
39 \\
48\end{array}$ & $\begin{array}{r}104 \\
110 \\
78\end{array}$ & $\begin{array}{r}84.5 \\
71.3 \\
121.4\end{array}$ & $\begin{array}{r}2 \\
44 \\
3\end{array}$ \\
\hline $\begin{array}{l}1158 \\
1172 \\
1173 \\
1174 \\
1175 \\
1220\end{array}$ & 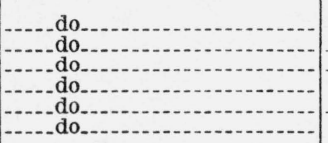 & $\begin{array}{l}\text { Prec. calcium carbonate } \\
\text { Natural calcium carbonate } \bar{A} \\
\text { Natural calcium carbonate } \bar{C}_{-}\end{array}$ & $\begin{array}{l}56.0 \\
56.9 \\
55.9 \\
56.7 \\
55.4 \\
55.4\end{array}$ & $\begin{array}{l}.0037 \\
.0039 \\
.0037 \\
.0037 \\
.0034\end{array}$ & $\begin{array}{r}7.2 \\
11.2 \\
21.1 \\
16.4 \\
9.9 \\
21.2\end{array}$ & $\begin{array}{l}.5 \\
1.6 \\
1.6 \\
.3 \\
1.3 \\
1.1\end{array}$ & $\begin{array}{l}9.6 \\
8.9 \\
8.8 \\
9.2 \\
8.5 \\
8.8\end{array}$ & $\begin{array}{r}0 \\
13 \\
6 \\
0 \\
23 \\
11\end{array}$ & $\begin{array}{l}90 \\
92 \\
93 \\
86 \\
87 \\
93\end{array}$ & $\begin{array}{r}49 \\
67 \\
116 \\
56 \\
51 \\
99\end{array}$ & $\begin{array}{r}96 \\
90 \\
69 \\
70 \\
103 \\
80\end{array}$ & $\begin{array}{r}101.1 \\
118.3 \\
128.3 \\
131.9 \\
104.9 \\
92.5\end{array}$ & $\begin{array}{r}29 \\
7 \\
6 \\
42 \\
43 \\
8\end{array}$ \\
\hline 1161 & Purified wood pulp: $A, 75 \%$; & Clay & 55.0 & .0034 & 11.5 & 1.6 & 6.1 & 24 & 88 & 59 & 109 & 62.7 & 25 \\
\hline $\begin{array}{l}1162 \\
1164 \\
1165\end{array}$ & 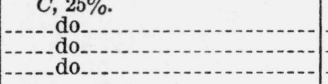 & \begin{tabular}{l}
-.do \\
\hdashline do... \\
\hdashline.- do...
\end{tabular} & $\begin{array}{l}57.4 \\
56.5 \\
58.1\end{array}$ & $\begin{array}{l}.0036 \\
.0033 \\
.0036\end{array}$ & $\begin{array}{l}11.9 \\
11.1 \\
11.9\end{array}$ & $\begin{array}{l}1.7 \\
1.1 \\
1.1\end{array}$ & $\begin{array}{l}5.6 \\
6.0 \\
5.6\end{array}$ & $\begin{array}{l}31 \\
13 \\
22\end{array}$ & $\begin{array}{l}87 \\
87 \\
88\end{array}$ & $\begin{array}{l}63 \\
63 \\
52\end{array}$ & $\begin{array}{l}114 \\
1118 \\
116\end{array}$ & $\begin{array}{l}65.8 \\
60.6 \\
65.6\end{array}$ & $\begin{array}{l}26 \\
27 \\
24\end{array}$ \\
\hline $\begin{array}{l}1168 \\
1169\end{array}$ & Purified wood pulp: $D, 100 \%$ & -.do-do & $\begin{array}{l}55.1 \\
56.9\end{array}$ & $\begin{array}{l}.0033 \\
.0036\end{array}$ & $\begin{array}{l}13.5 \\
13.9\end{array}$ & $\begin{array}{l}.9 \\
.9\end{array}$ & $\begin{array}{l}6.4 \\
5.8\end{array}$ & $\begin{array}{l}14 \\
17\end{array}$ & $\begin{array}{l}83 \\
84\end{array}$ & $\begin{array}{l}28 \\
28\end{array}$ & $\begin{array}{l}8300 \\
8300\end{array}$ & $\begin{array}{r}9.5 \\
11.3\end{array}$ & $\begin{array}{l}40 \\
41\end{array}$ \\
\hline
\end{tabular}




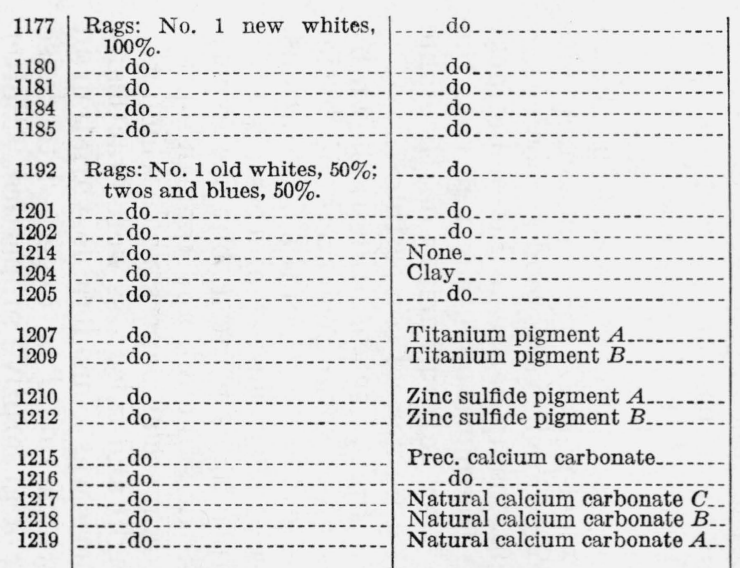

Commercial machine-finish book (Government Printing Office) Commercial offset book (Government Printing Office)

\section{On oven-dry basis.}

Cold water extraction, unpublished method.

Tests made at 65-percent relative humidity and $70^{\circ} \mathrm{F}$.
A verages of measurements on both felt and wire sides of sheets.

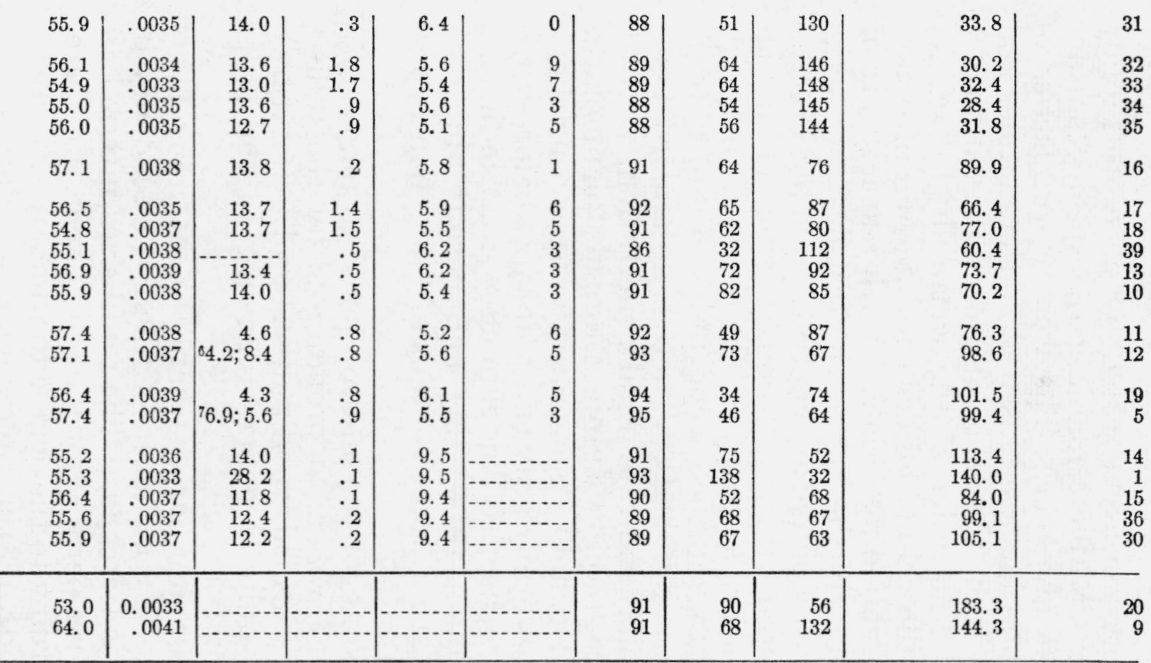

${ }^{8}$ Relative amounts, in increasing order.

Titanium dioxide and barium sulfate, respectively.

8 Fnd 
The papers containing fillers were penetrated by oil more rapidly than the papers without fillers. Fillers increase the specific surface of the absorptive constituents of paper. The wetting properties of the fillers and the cellulose materials used, as well as the number and size of the minute channels within the sheet also doubtless influence the rate of oil penetration. The order of the wettability of either fillers or fibers may differ in the cellulose-filler combination of paper, however, from that of the individual materials. With respect to their influence on the oil penetrability of the paper, the test data show the order of the fillers, in decreasing rapidity of penetration, to be: Precipitated calcium carbonate, natural calcium carbonate, zinc sulfide pigments, titanium dioxide pigments, and clay. The order of the pulps is: Old rags, sulfite-soda mixture, purified wood pulps $A$ and $C$ (mixture), new rags, and purified wood pulp $D$. There is no apparent correlation between degree of sizing and rate of oil penetration.

In the test of the papers containing titanium dioxide pigment the oil seemed to take considerable time to penetrate the upper surface of the sheet and also to form a uniformly gray end point just before penetrating the lower surface of the sheet. This skin effect may indicate a higher resistance of the pigment to wetting and permit obtaining comparable printing results with a lower content of filler than is possible with other kinds of fillers.

The sharpness of the end point for the oil-drop penetration, regardless of the type of filler present, was most pronounced for the sulfitesoda papers, with the old rag, purified wood pulps $A$ and $C$ (mixture), new rag, and purified wood pulp $D$ papers following in the order given.

The air permeability was greater for the papers containing fillers than for those without fillers. By inclusion of fillers the tendency of the fibers to cement together is lessened. The number of internal air spaces, and consequently the air permeability of the paper, are therefore increased. Ranked according to the degree to which they increase air permeability, the fillers are in the following descending order: Precipitated calcium carbonate, natural calcium carbonate, zinc sulfide pigment, titanium dioxide pigment, and clay, although only slight differences are shown for the last three. The corresponding order for the pulps is: Sulfite-soda, old rag, purified wood pulps $A$ and $C$ (mixture), new rag, and purified wood pulp $D$. The measurements for the individual sheets of the sample were in very good agreement.

There appears to be a definite relationship between the air-permeability and the oil-penetration data, the more open sheet having the more rapid oil penetration, but too few measurements on the same type of paper were made to warrant a numerical correlation.

The net resultant of all the factors that affect printing is shown by actual printings. In general, the offset printings were of better quality than the letterpress, and the text better than the illustrations. The ink and the mechanical phases of the printing process are ordinarily adjusted for each specific paper to be printed, but the experimental papers were all printed with the same ink and the same press adjustments - those used for the commercial papers with which the test sheets were run. The basis weight and thickness were practically uniform for all the papers, but there was considerable variation in their fiber and filler composition, which would be expected to cause the papers to have different wetting or absorptive properties. Better 
ratings are therefore given for the offset printings because smaller, and more nearly uniform, amounts of ink were used. It is believed that printing conditions could have been adjusted to suit each type of paper, and that more satisfactory results would then have been obtained with either process.

The appearance of the text was satisfactory for all the offset printings. With some of the papers there was "show through" of the cuts, that is, print was visible on the opposite side of the sheet. The table gives ratings of the offset printings as to relative amount of "show through," in increasing order. The ratings were determined by visual observation. Although each of the printings is assigned a specific position in the series, several could be grouped as of practically the same quality.

The paper of machine run 1216 was rated as freest from "show through." This paper was made from a pulp furnish of old rags with a relatively high percentage of calcium carbonate. Next in rank were the papers of runs 1150 and 1153 . These, and the remaining samples containing zinc sulfide pigments were considerably darker in color ${ }^{4}$ than the other papers, however, and their rating on "show through" might not have been the same if they had been lighter-colored. The rating of the samples containing titanium dioxide pigments was in agreement with the behavior noted in the oil-penetration test. Since the initial rate of penetration is slow, the ink must be carefully controlled to prevent "set off" and smudging, but there should be little "show through."

For letterpress printing the calcium carbonate-filled papers gave the best results. As to "show through" the letterpress printings were in approximately the same order as the offset. Disagreements were in general attributed more to variations in the amount of ink on the images than to the paper.

The papers made from the mixture of purified wood pulps $A$ and $C$ were about the same as the sulfite-soda and the old-rag, all being satisfactory. A tendency of the ink to "lift" or "pick" was noted for the harder papers, but as the ink was adjusted to comparatively soft paper, it doubtless was not strong, or tacky, enough for these sheets. The papers made from purified wood pulp $D$ were too hard for book paper, as noted in the previous publication, ${ }^{5}$ because of too rapid hydration of the pulp during the beating. The new-rag papers were only fair, also doubtless because of the method of stock preparation. Quicker beating would have produced softer paper, with greater air permeability and more rapid oil penetration, and as a result, improved printability.

The color of the paper influenced the evaluation of clearness of print-letterpress or offset-to some extent, the whiter samples ranking higher than the natural colored. For some of the papers the difference in color was caused by differences in the pulps used, but for those having the same pulp furnish the difference was due to the fillers. No dye was used for tinting any of the papers.

\footnotetext{
4 As explained in RP1149, the darker color of these papers was attributed to the conper lining of the beater and the acidic condition of the pulp during the preparation of the stock. As a precautionary measure the supplier of the zine sulfide pigments recommends that plants having considerable copper equipment "avoid acid conditions so excessive as to attack this equipment and to form a dilute copper solution, as such a condition can dull down the white pigment to an extent dependent upon the amount of copper in solution and the time available for the reaction." Since the program of study included the manufacture at pH 4.2 of some papers with each filler, dulling of the papers pigmented with zine sulfide was expected.

s. Research NBS 21, 671 (1938) RP1149.
} 
Printing trials are the ultimate criteria for evaluating the printing quality of paper, but laboratory tests should enable the manufacturer to ascertain before shipment of his paper that it will have the requisite printing properties. Opacity and smoothness are known to be related to printing quality and therefore have a place in paper specifications. Less is known of the relation of oil penetration and air permeability, but it is believed that they also are indicative of the behavior of paper in actual printing. As data on these tests are accumulated for different types of filler and pulp furnishes and correlated with the quality of printing, it may be found that numerical specifications of these additional properties can be included to aid in controlling printing quality within predetermined limits.

The authors acknowledge their indebtedness to the following members of the Bureau: R. W. Carr, M. J. O'Leary, and V. Worthington for assistance in the preparation and testing of the papers, and to M. N. V. Gerb and C. G. Weber for rating the printings.

Washington, January 4, 1939. 